\title{
Burning Characteristics and Mechanical Properties of AP/HTPB Propellant Containing Glycerin as a Plasticizer
}

\author{
By Makoto KoHGA and Kayoko ОкамотO \\ Department of Applied Chemistry, The National Defense Academy, Yokosuka, Japan
}

(Received April 17th, 2008)

\begin{abstract}
The improvement of the performance of composite propellant has been required due to the development of a wide variety of rockets and missiles. Glycerin has three oxygen atoms in its molecular structure, and it is a safe and low-viscosity material. Therefore, it is expected that glycerin would be one of candidates as a plasticizer of an AP/HTPB based-propellant. The burning characteristics and the mechanical properties of AP/HTPB propellant containing glycerin were investigated in this study. The viscosity of the uncured propellant containing glycerin was lower than that without glycerin. The tensile properties were improved with the small added quantity of glycerin. The burning rate of the propellant at 70\%AP increased with the addition of glycerin and the propellant containing glycerin had a plateau burning characteristics. It was found that the addition of glycerin as a plasticizer would be an effective way to improve the burning characteristics, mechanical properties, and processability of the AP/HTPB propellant.
\end{abstract}

Key Words: Composite Propellant, Burning Characteristics, Mechanical Property, Plasticizer, Glycerin

\section{Nomenclature}

\section{$\xi \quad$ :glycerin/HTPB mole ratio}

\section{Introduction}

Development of a wide variety of rockets and missiles has required development of propellants having a wide range of performance corresponding to the purposes for which they are used. Especially, a high burning rate propellant is needed when developing a high performance rocket motor. The use of burning rate modifiers, metal fuels and high energetic materials is a typical method to obtain a high burning rate propellant.

It is expected that the burning rate of composite propellant is also enhanced by the increase in the amount of oxygen in fuel binder. A plasticizer is a liquid organic compound, which also acts as a fuel, or liquid energetic compounds (containing oxygen, azide, or nitrate groups), which add energy to the propellant. The plasticizer is usually a relatively low-viscosity liquid ingredient that is added to improve the mechanical properties of the propellant and to improve processing properties, such as lower viscosity for mixing and casting or longer pot life of the uncured propellants.

Glycerin has three oxygen atoms in its molecular structure. For the composite propellant containing glycerin, the burning characteristics would be improved by the contribution of oxygen atoms in glycerin molecular to the propellant combustion. Furthermore, it was expected that the processability of propellant would be improved by the addition of glycerin as a plasticizer to НTPB due to a lower viscosity of glycerin/HTPB compared with HTPB alone.
In the previous paper ${ }^{1)}$, it was investigated the curing behavior, the mechanical properties, and the thermal decomposition of glycerin/HTPB blend. And it was found that this blend would be an effective fuel binder for a composite propellant. The glycerin/HTPB blend was hard enough to use a binder for a composite propellant when the glycerin/HTPB mole ratio, $\xi$, was below 10 .

At the AP content of $50,60,70$, and $80 \%$, the theoretical performance of AP/HTPB-based propellant without/with glycerin $(\xi=10)$ was estimated using NASA SP273 program ${ }^{2)}$. At 50 and $60 \% \mathrm{AP}$, these values of the propellant containing glycerin are lower than those of the propellant without glycerin. This was because these propellants would not generate a heat enough to burn the fuel ingredients with glycerin due to the low AP content. On the other hand, these values of the propellant at 70 and $80 \% \mathrm{AP}$ are increased by the addition of glycerin. It was expected the addition of glycerin to HTPB would be effective to improve the performance of AP/HTPB-based propellant above $70 \%$ AP. In this study, the AP/HTPB-based propellant containing glycerin at 70 and $80 \%$ AP was prepared and the processability, the mechanical properties, and the burning rate characteristics of these propellants were investigated. Details of these investigations are reported in this paper.

\section{Experiment}

\subsection{Sample}

The glycerin/HTPB blend below $\xi$ of 10 was hard enough to use a binder for a composite propellant ${ }^{1)}$. The value of $\xi$ was $0,0.5,2.5,5.0$, and 10.0 in this study. The AP content of the propellant is 70 and $80 \%$. Table 1 shows the propellant formulations. The compatibility 
between AP and glycerin/HTPB blend was not good. The addition of sodium lauryl sulfate is effective to improve the wettability between AP and $\mathrm{HTPB}^{3)}$. Sodium lauryl sulfate was added $0.5 \%$ of HTPB to the blend to improve the compatibility. IPDI was added at $8 \%$ of HTPB, i.e., a ratio of the NCO group of IPDI to the $\mathrm{OH}$ group of HTPB was 1.2. Glycerin has a hygroscopic material. The moisture in glycerin was removed with molecular sieves before the addition of glycerin to the HTPB.

Table 1 Formulation of propellants

\begin{tabular}{ccccc}
\hline Propellant & $\begin{array}{c}\text { AP } \\
(\%)\end{array}$ & $\begin{array}{c}\text { HTPB } \\
(\%)\end{array}$ & $\begin{array}{c}\text { Glycerin } \\
(\%)\end{array}$ & $\begin{array}{c}\xi \\
(-)\end{array}$ \\
\hline A & 70 & 30.00 & - & 0 \\
B & 70 & 29.59 & 0.41 & 0.5 \\
C & 70 & 28.03 & 1.97 & 2.5 \\
D & 70 & 26.30 & 3.70 & 5.0 \\
E & 70 & 23.42 & 6.58 & 10.0 \\
F & 80 & 20.00 & - & 0 \\
G & 80 & 19.72 & 0.28 & 0.5 \\
H & 80 & 18.69 & 1.31 & 2.5 \\
I & 80 & 17.54 & 2.46 & 5.0 \\
J & 80 & 15.61 & 4.39 & 10.0 \\
\hline
\end{tabular}

\subsection{Analytical Method}

The apparent viscosities of uncured propellant were measured by a flow tester of capillary type. The measurement of apparent viscosity was conducted at 333 $\mathrm{K}$ using a die with $\phi 1 \times 1 \mathrm{~mm}$ under a load of $1.96 \mathrm{MPa}$ for the propellant at $70 \% \mathrm{AP}$ and that of $2.94 \mathrm{MPa}$ for the propellant at $80 \% \mathrm{AP}$

The mechanical properties of the cured blend were investigated by a tension test and a hardness test. Mechanical properties were averaged form four measurements. The tensile test was carried out using dumb-bells at a cross-head speed of $5 \mathrm{~mm} / \mathrm{min}$ at $293 \mathrm{~K}$ with an autograph on the basis of Japan Explosives Society Standard PT-008. The values of ultimate tensile strength and ultimate tensile strain were obtained for each sample. The hardness test was made measurements on the basis of ASTM D2240. The hardness was measured at 253, 279, 298, and $333 \mathrm{~K}$ using a Durometer Type 00 rubber hardness tester.

Thermochemical behaviors of the binder and the propellant were investigated by differentical thermal analysis (DTA) and thermogravimetry(TG). The equipment was operated in a nitrogen flow condition at atmospheric pressure. The sample containers for the equipment were made of aluminum. The heating rate was $20 \mathrm{~K} / \mathrm{min}$.

The size of each strand was $10 \mathrm{~mm} \times 10 \mathrm{~mm}$ in cross section and $40 \mathrm{~mm}$ in length. The side of each strand was inhibited by silicon resin. The burning rate was measured in a chimney-type strand burner which was pressurized with nitrogen. The initial temperature of propellant was approximately $288 \mathrm{~K}$. The range of pressure was from $0.5 \mathrm{MPa}$ to $7 \mathrm{MPa}$. The strand sample was ignited by an electrically heated nichrome wire attached on the top of each strand sample. Two fuse wires were threaded through the strand sample at $25 \mathrm{~mm}$ distance. The fuse wire cut as soon as the burning surface passes through the fuse wire. The burning rate was calculated with the cutoff period of two fuses.

\section{Results and Discussion}

\subsection{Viscosity}

Figure 1 shows the apparent viscosities of the uncured propellant versus time. These viscosities increase with increasing time. For the propellant at $70 \% \mathrm{AP}$, the viscosity of the propellant at $\xi$ of 10 is slightly lower than that without glycerin. The effect of glycerin on the reduction of the viscosity scarcely appeared because of the high binder content. On the other hand, the viscosity of the propellant at $80 \%$ AP decreases with increasing $\xi$. The apparent viscosities of propellant F, G, and J at the immediately after heating are 189, 110, and 74 Pas, respectively. The viscosity of propellant $\mathrm{J}$ (the uncured propellant at $\xi$ of 10 ) is approximately half of that of propellant $F$ (the uncured propellant without glycerin). The viscosity of the uncured propellant at $80 \% \mathrm{AP}$ remarkably decreased with the small addition of glycerin compared to the uncured propellant at $70 \% \mathrm{AP}$.
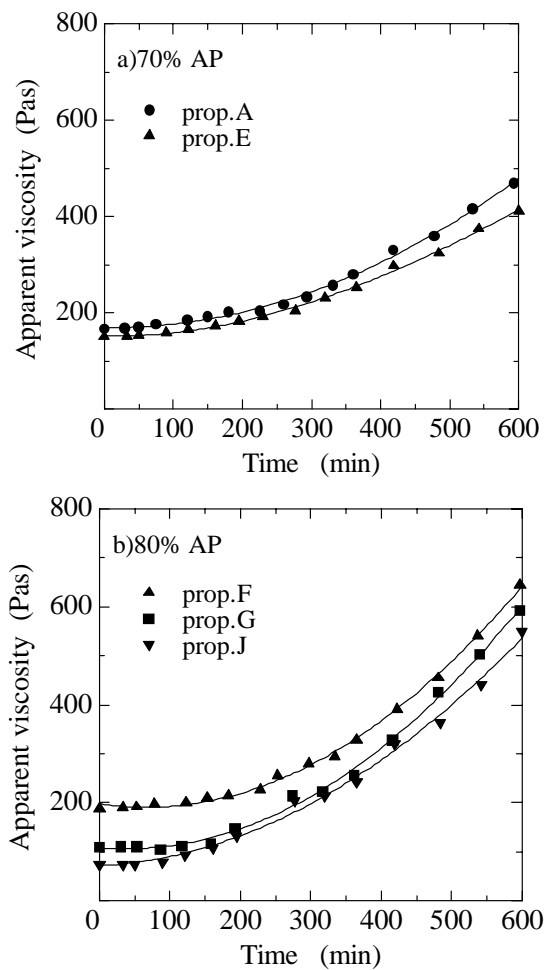

Fig. 1 Curing character tics of uncured propellant

These facts indicate that the addition of glycerin would be effective not only to decrease the processing viscosity of the AP/HTPB-based composite propellant, but also to extend the pot life.

\subsection{Mechanical Properties}

Table 2 shows the hardness of propellant A, E, F, and J. The hardness of the propellant at $80 \% \mathrm{AP}$ is a little higher than that at 70\%AP because of the larger content of AP as a solid loading. The hardness decreases slightly with 
increasing temperature and $\xi$. The hardness of the glycerin/HTPB blend at $\xi$ of 10 was approximately half of that of HTPB alone at $333 \mathrm{~K}^{1)}$, however, the hardness of the propellant was scarcely decreased by using of the glycerin/HTPB blend as a binder. This was because these propellants had a large quantity of AP as filler. This result suggested that the reduction of the hardness of the binder would hardly contribute to the decrease in the hardness of the composite propellant at a larger solid loading.

Table 2 Influence of temperature on Hardness of propellants A, E, F, and J

\begin{tabular}{|c|c|c|c|c|}
\hline \multirow{2}{*}{ Propellant } & \multicolumn{4}{|c|}{ Hardness $\quad(-)$} \\
\hline & $253 \mathrm{~K}$ & $278 \mathrm{~K}$ & $293 \mathrm{~K}$ & $333 \mathrm{~K}$ \\
\hline A & 86 & 86 & 85 & 83 \\
\hline E & 86 & 85 & 82 & 80 \\
\hline $\mathrm{F}$ & 91 & 91 & 89 & 89 \\
\hline $\mathrm{J}$ & 89 & 88 & 87 & 86 \\
\hline
\end{tabular}

Figure 2 shows the tensile properties of the propellant. For the propellant at $70 \% \mathrm{AP}$, the ultimate tensile strength remarkably decreases below $\xi$ of 1 , while above this value, it is almost constant. The tensile strain increases, especially greatly below $\xi$ of 1 . For the propellant at $80 \% \mathrm{AP}$, the ultimate tensile strength remarkably decreases below $\xi$ of 1 , while above that, it gently decreases. The tensile strain greatly increases below $\xi$ of 1 , while above that, it gently increases. It is found that the ultimate tensile strain and strength significantly vary with the small quantity of glycerin below $\xi$ of 1 .
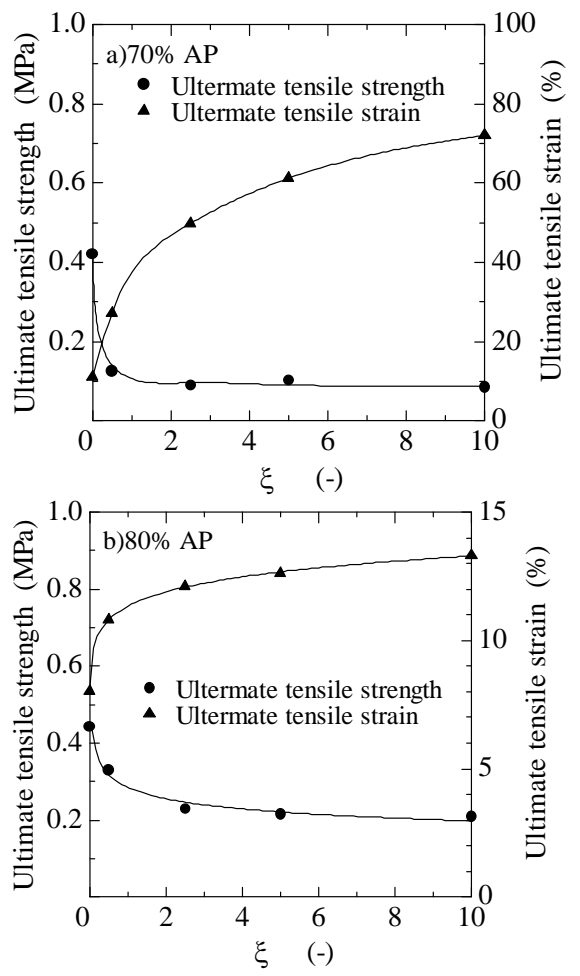

Fig. 2 Tensile properties

For the propellant at $70 \% \mathrm{AP}$, the ultimate tensile strength and strain of the propellant without glycerin are
$0.42 \mathrm{MPa}$ and $11 \%$, and those of the propellant at $\xi$ of 10 are $0.09 \mathrm{MPa}$ and $72 \%$. For the propellant at $80 \% \mathrm{AP}$, the ultimate tensile strength and strain of the propellant without glycerin are $0.44 \mathrm{MPa}$ and $8 \%$, and those of the propellant at $\xi$ of 10 are $0.21 \mathrm{MPa}$ and $13 \%$. The ultimate tensile strength and strain of the propellant without glycerin at $70 \% \mathrm{AP}$ were almost the same as these values at $80 \%$ AP respectively. However, there was a difference in the tensile properties of the propellant at $\xi$ of 10 between the propellant at $70 \% \mathrm{AP}$ and that at $80 \% \mathrm{AP}$, and especially, the ultimate tensile strain of the propellant at $70 \%$ AP was much larger than that of the propellant at $80 \%$ AP. It was found that the tensile properties of the propellant with glycerin depended on the AP content.

\subsection{Thermal Decomposition Behavior}

Figure 3 shows the DTA-TG thermograms of the propellants A, E, F, and J. According to the DTA curve, the endothermic peak is observed around $517 \mathrm{~K}$ due to the crystal transformation of AP, and then the propellant decomposes exothermically and the peak is in the range of 684-688 K. The DTA curve of the propellant at $80 \%$ AP is almost the same as that at $70 \% \mathrm{AP}$.
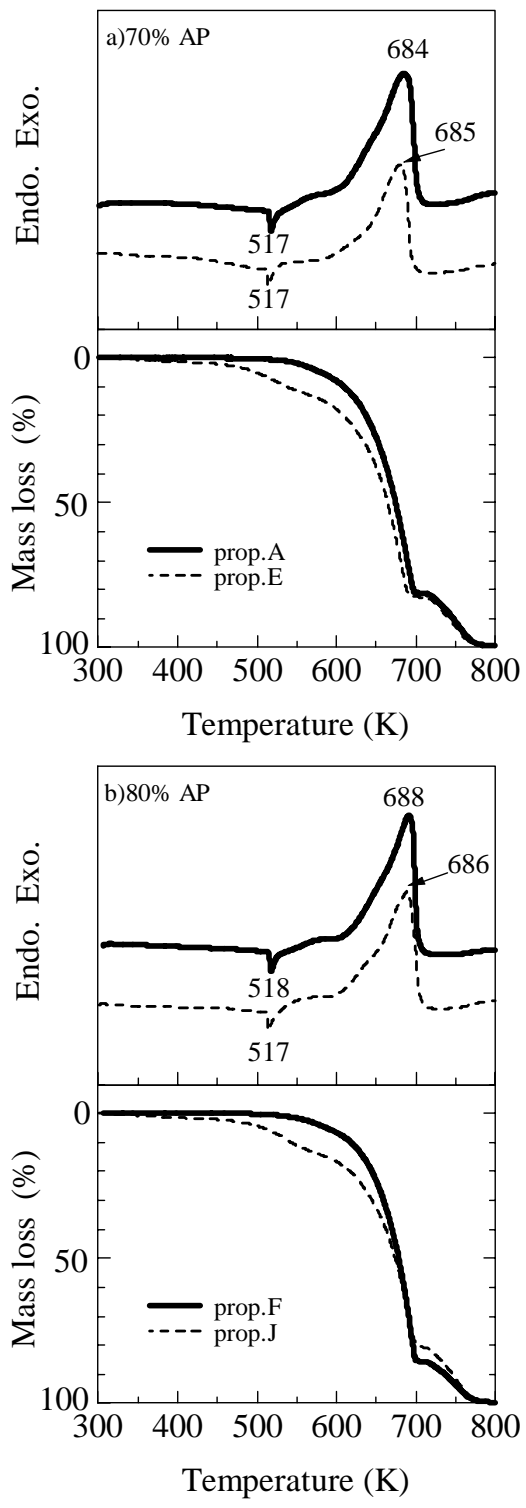

Fig. 3 DTA-TG curves 
From the TG curve, the main mass loss of these propellants is observed in the range of $600-700 \mathrm{~K}$. The consumption of approximately $80-90 \%$ occurs below approximately $700 \mathrm{~K}$ and the propellant completely consumes around $800 \mathrm{~K}$. The beginning temperature of consumption of the propellant containing glycerin (propellants $\mathrm{E}$ and $\mathrm{J}$ ) is lower than that of the propellant without glycerin (propellants A and F). Propellants E and $\mathrm{J}$ consume approximately $15 \%$ below $600 \mathrm{~K}$ and this consumption is not observed on the TG curves of propellants $\mathrm{A}$ and $\mathrm{F}$. The beginning temperature of consumption of the cured glycerin/HPB blend is lower than that of the cured HTPB alone ${ }^{1)}$. The consumption at lower temperature for the propellant with glycerin would become greater by the improvement of the thermal decomposition of the glycerin/HTPB blend.

It is found that the thermal decomposition behavior of the AP/HTPB-based propellant containing glycerin is superior to that of AP/HTPB-based propellant without glycerin. These results suggest that the addition of glycerin would allow the AP/HTPB-based propellant to enhance the burning rate.

\subsection{Burning Characteristics}

Figure 4 shows the burning rate characteristics of propellants A, E, F, and J. The burning rate of propellant $\mathrm{E}$ is higher than that of propellant $\mathrm{A}$ and the burning rate of the propellant at $70 \% \mathrm{AP}$ increases with increasing $\xi$. Propellant $\mathrm{E}$ has a plateau burning characteristics between 4 and $7 \mathrm{MPa}$. On the other hand, the burning rate of propellant $\mathrm{J}$ is almost the same as that of propellant F. Thus the burning rate of the propellant at $80 \%$ AP (propellants F-J) is almost constant. These results indicated that the addition of glycerin was effective to increase the burning rate of the propellant at $70 \%$ AP, however, the burning rate of propellant at $80 \%$ AP was not enhanced by the addition of glycerin.

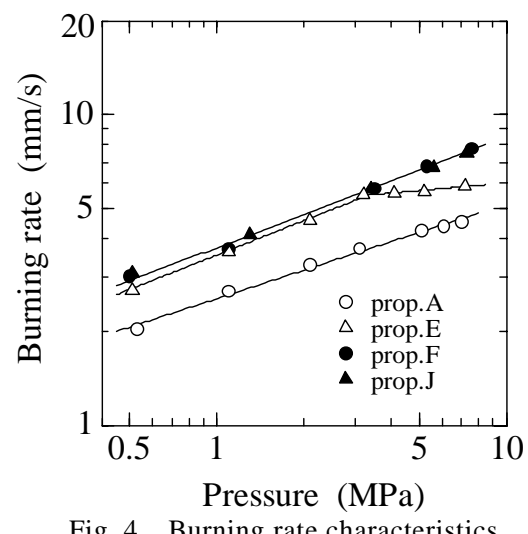

The combustion of AP/HTPB-based composite propellant is controlled by the diffusion and mixing processes of the decomposed gases of AP and the surrounding HTPB at burning surface. These decomposed gases react and produce heat on and above the burning surface to form diffusional flame. It was expected the burning rate would be increased by an improvement of the thermal decomposition of the propellant. From the TG curve, the consumption below $600 \mathrm{~K}$ of the propellant containing glycerin was larger than that of the propellant without glycerin as described in section 3.3. The improvement of the thermal decomposition behavior at lower temperature would allow the propellant to enhance the burning rate.

The AP/HTPB-based composite propellant generates the decomposed gases of AP and HTPB at burning surface during combustion. The AP particles decompose to produce perchloric acid, $\mathrm{HClO}_{4}$, and the HTPB binder decomposes to produce hydrocarbon fragments and hydrogen ${ }^{4)}$. These decomposed gases react and produce heat on and above the burning surface. An endothermic reaction takes place involving pyrolysis of the binder to form gaseous product (fuel) and dissociative sublimation and/or decomposition of AP to form ammonia and perchloric acid at the burning surface. The fuel and oxidizer components diffuse and mix together above the burning surface to form diffusional flamelets and/or premixed flame and produce final combustion products such as $\mathrm{CO}, \mathrm{CO}_{2}, \mathrm{H}_{2} \mathrm{O}, \mathrm{HCl}, \mathrm{N}_{2}$, et al.

The combustion products were theoretically estimated using NASA SP273 program ${ }^{2)}$. Figure 5 shows the influence of $\xi$ on the principal combustion products. For the propellant at $70 \% \mathrm{AP}$, the generation of graphite was estimated. Actually, a lot of soot remained in the combustion chamber after the combustion test of the propellant. This suggests that the fuel ingredients do not burn completely. The mole fraction of graphite obviously decreases and that of $\mathrm{CO}_{2}$ and $\mathrm{H}_{2} \mathrm{O}$ slightly increases when $\xi$ increases. On the other hand, the propellant at $80 \%$ AP does not theoretically generate graphite, and the mole fraction of $\mathrm{H}_{2}$ and $\mathrm{CO}$ decreases and that of $\mathrm{H}_{2} \mathrm{O}$ increases when $\xi$ increases.

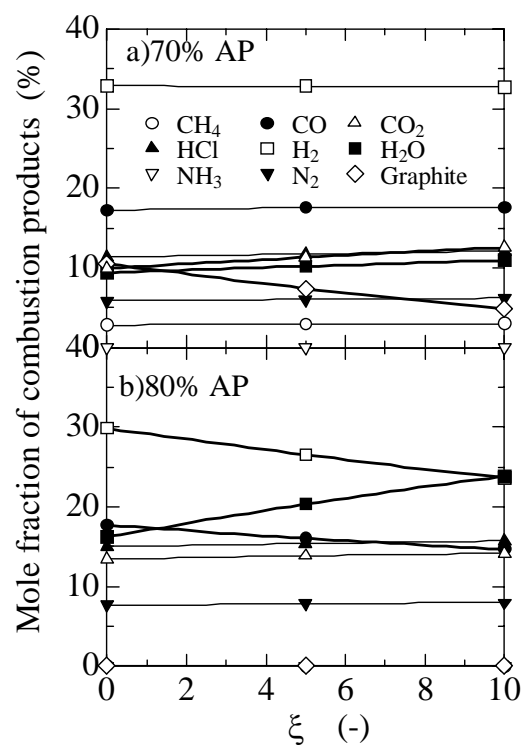

Fig. 5 Influence of $\xi$ on combustion products

As mentioned above, the fuel ingredients in the propellant at $70 \%$ AP does not burn completely and graphite is generated. The amount of graphite theoretically decreases with increasing $\xi$. The burning characteristics would be improved by the addition of 
glycerin because the fuel ingredients were burned with glycerin in the propellant. Both the heat generated at the burning surface and the heat feedback from the gas phase per unit time would be increased by the improvement of the thermal decomposition behavior and burning characteristics of the propellant. Therefore, the burning rate of the propellant at $70 \% \mathrm{AP}$ would be increased by the addition of glycerin.

On the other hand, the propellant at $80 \%$ AP does not theoretically generate graphite, and the proportion of $\mathrm{H}_{2}$ and $\mathrm{CO}$ is decreased and that of $\mathrm{H}_{2} \mathrm{O}$ is increased by the addition of glycerin. This suggests the burning characteristics of the propellant at $80 \%$ AP were also improved by the addition of glycerin in a similar manner to the propellant at $70 \%$ AP.

Thus the propellant at $80 \%$ AP has the AP content enough to burn the fuel ingredients. For the propellant at $80 \% \mathrm{AP}$, the heat generated on and above the burning surface is sufficiently large due to the high AP content, and the heat generated at the burning surface and the heat feedback form the gas phase per unit time are large. Therefore, the burning rate of the propellant at $80 \% \mathrm{AP}$ with glycerin was not higher than that of the propellant without glycerin even though the thermal decomposition at lower temperature and the burning characteristics were improved by glycerin.

As shown in Fig.4, propellant E has the unique burning characteristics, that is, the plateau burning characteristics between 4 and $7 \mathrm{MPa}$. Unfortunately the reason could not be elucidated in this study.

\section{Conclusions}

The burning characteristics, mechanical properties, and processability of AP/HTPB propellant containing glycerin as a plasticizer were investigated in this study. The results are as follows; 1) The viscosity of the uncured propellant containing glycerin was lower than that without glycerin. The addition of glycerin is effective not only to decrease the processing viscosity of the
AP/HTPB-based composite propellant, but also to extend the pot life. 2) The hardness of the propellant was scarcely decreased by using of the glycerin/HTPB blend as a binder. The tensile properties significantly vary with the small added quantity of glycerin. 3) The consumption at lower temperature for the propellant with glycerin became greater compared to that for the propellant without glycerin. It is found that the thermal decomposition behavior of the AP/HTPB-based propellant containing glycerin is superior to that of AP/HTPB-based propellant without glycerin. 4) The burning rate of the propellant at $70 \%$ AP increased with the addition of glycerin, while the burning rate of the propellant at $80 \%$ AP with glycerin is not higher than that of propellant without glycerin. The propellant containing glycerin at $70 \%$ AP has a plateau burning characteristics. 5) The burning characteristics were improved and the specific impulse was increased by the addition of glycerin to AP/HTPB-based propellant.

The addition of glycerin as a plasticizer would be an effective way to improve the burning characteristics, mechanical properties, and processability of the AP/HTPB propellant.

\section{References}

1) Kohga, M.: HTPB/Glycerin Blend for Binder, Meeting of Japan Explosives Society, Japan, Okinawa, 2003. Nov., pp.79-80.

2) Gordon, S., McBride, B.J.: Computer Program for Calculation of Complex Chemical Equilibrium Compositions, Rocket Performance, Incident and Reflected Shocks, and Chapman-Jouguet Detonations, NASA SP-273, 1971, NASA Lewis Research Center, Wasington,D.C., WA, USA.

3) Kohga, M., Hagihara, H.: Effects of Addition of Surfactants on Viscosity of Uncured Ammonium Perchlorate/Hydroxylterminated Polybutadiene Propellant, Kayaku Gakkaishi, 59 (1998), pp.167-173.

4) Kubota, N.: Propellants and Explosives, WILEY-VCH GmbH, Weinheim, Germany, 2002, p.157. 